\title{
Analisis Perencanaan Sistem Informasi Menggunakan Metode Ward And Peppard Pada Universitas Kristen Indonesia Maluku
}

\author{
Analysis of Information Systems Planning Using the Ward And Peppard Method \\ at the Indonesian Christian University in Maluku \\ Janeman Sumah*1, Wing Wahyu Winarno ${ }^{2}$, Mei P. Kurniawan ${ }^{3}$ \\ ${ }^{1,2,3}$ Universitas Amikom Yogyakarta \\ ${ }^{1}$ Magister Teknik Informatika, ${ }^{2,3}$ Universitas Amikom Yogyakarta \\ e-mail: *1janeman.28@ students.amikom.ac.id, ${ }^{2}$ wing@ @stieykpn.ac.id, \\ meikurniawan@amikom.ac.id,
}

\begin{abstract}
Abstrak - Dalam upaya mencapai tujuan Universitas Kristen Indonesia Maluku yang terumuskan dalam visi dan misi, yakni meningkatkan perluasan akses pendidikan tinggi secara kualitas dan kuantitas demi mewujudkan idiealisme Universitas Kristen Indonesia Maluku sebagaimana terumus di dalam Pola Ilmiah Pokok Universitas Kristen Indonesia Maluku yakni "daya darma masyarakat kepulauan", dimana masyarakat di Kepulauan Maluku memiliki kemampuan iptek, inovasi, keunggulan dan daya saing dalam kerangka nasionalisme Indonesia." Universitas Kristen Indonesia Maluku memerlukan strategi bisnis maupun strategi Sistem Informasi. Maka dari itu diperlukan perencanaan strategis Sistem Informasi untuk mendukung keberhasilan visi, misi dan tujuan organisasi dibidang pendidikan Salah satunya adalah perlu adanya sebuah portofolio aplikasi informasi yang merupakan hasil dari analisis perencanaan strategis sistem informasi pada lingkungan Universitas Kristen Indonesia Maluku. Tujuan penelitian ini adalah untuk merumuskan rencana strategis sistem informasi pada lingkungan Universitas Kristen Indonesia Maluku berupa portofolio aplikasi / sistem informasi untuk masa yang akan datang menggunakan framework metode Ward and Peppard dengan bantuan tools yang dipakai yaitu: analisis SWOT, Value Chain, Critical Success Factor (CSF), Porter Five Forces model, dan portofolio McFarlan grid. Adapun hasil analisa akhir, Universitas Kristen Indonesia Maluku memerlukan sepuluh jenis aplikasi sistem informasi baru yang direncanakan akan dibuat, enam belas aplikasi yang dipertimbangkan untuk diperbaharui, dan usulan model arsitektur jaringan enterprise berbasis Cloud yang dapat dijadikan sebagai langkah awal untuk mencapai sasaran strategis Universitas Kristen Indonesia Maluku, selain itu dapat dijadikan pedoman agar arah kebijakan pengembangan sistem informasi menjadi terukur dan jelas
\end{abstract}

Kata kunci - Critical Success Factor (CSF); McFarlan Grid; Porter Five Forces Model; SWOT; Ward and Peppard

\begin{abstract}
In an effort to achieve the goals of the Maluku Indonesia Christian University which are formulated in the vision and mission, namely increasing the expansion of access to higher education in quality and quantity in order to realize the idealism of the Indonesian Christian University of Maluku as formulated in the Principal Scientific Pattern of the Indonesian Christian University of Maluku, namely "the power of the community islands ", where people in the Maluku Islands have the ability to science and technology, innovation, excellence and competitiveness within the framework of Indonesian nationalism." The Christian University of Indonesia Maluku needs a business strategy as well as an IS strategy. Therefore, IS strategic planning is needed to support the success of the vision, mission and goals of the organization in the field of education. One of them is the need for a portfolio of information applications which is the result of the analysis of strategic planning for information systems at the Indonesian Christian University in Maluku. The purpose of this research is to formulate a strategic plan for information systems at the Indonesian Christian University of Maluku in the form of a portfolio of applications / information systems for the future using the Ward and Peppard method framework with the help of the tools used, namely: SWOT analysis, Value Chain, Critical Success Factors ( CSF), the Porter Five Forces model, and the McFarlan portfolio grid. As for the results of the final analysis, the Indonesian Christian University of Maluku requires ten types of new information system applications that are planned to be made, sixteen applications that are considered for renewal, and a proposed cloud-based enterprise network architecture model that can be used as a first step to achieve the strategic goals of the Indonesian Christian University. Maluku, besides that it can be used as a guideline so that the direction of information system development policies becomes measurable and clear.
\end{abstract}

Keywords - Critical Success Factor (CSF); McFarlan Grid; Porter Five Forces Model; SWOT; Ward and Peppard 


\section{PENDAHULUAN}

Dalam perkembangan dunia pendidikan saat ini, penerapan dari SI/TI telah memegang peranan penting untuk mencapai keberhasilan. Merencanakan sebuah Strategi untuk sebuah Universitas merupakan bagian yang sangat penting dan harus dilakukan oleh semua universitas yang ada. Dalam menjawab tantangan untuk menjadi Universitas Unggul, maka Universitas Kristen Indonesia Maluku dituntut untuk menyelaraskan proses dan sistem yang dimiliki. Dari sisi Sistem Informasi, Universitas Kristen Indonesia Maluku telah memiliki Sistem Informasi Akademik Terpadu, dan Sistem Informasi Jurnal dan Artikel. Jika dilihat dari perkembangan sistem informasi terkini, maka masih ada sistem informasi tambahan yang perlu dikembangkan dalam rangka memenuhi tiga aspek pendidikan perguruan tinggi (pengajaran, penelitian, dan pengabdian masyarakat).

Institusi yang ingin menerapkan sistem informasi harus berfokus pada keselarasan dengan bisnis, untuk itu diperlukan suatu perencanaan strategis sistem informasi agar menjamin keselarasan antara keduanya, yaitu tujuan bisnis dan sistem informasi. Organisasi yang ingin memperbaiki atau memperbaharui infrastruktur, maupun mengoptimalkan manfaat Sistem Informasi dan Teknologi Informasi (SI/TI) sebaiknya melakukan perencanaan strategis (Henderson \& Sifonis, 1988) [1].

Dari sisi Teknologi Informasi, Universitas Kristen Indonesia Maluku telah memiliki jaringan internet yang terkoneksi ke fasilitas rektorat, puskom, pustaka dan fakultas-fakultas yang ada. Dalam upaya mencapai tujuan yang terumuskan dalam visi dan misi, Universitas Kristen Indonesia Maluku memerlukan strategis bisnis maupun strategis SI. Melihat kondisi saat ini, penulis berkeinginan untuk membangun suatu perencanaan kebutuhan SI agar pembangunan SI di Universitas Kristen Indonesia Maluku dapat dilakukan secara terencana serta dapat mengintegrasikan kebutuhan informasi disana. Perencanaan strategis sistem dan teknologi informasi yang penulis teliti dibuat berdasarkan framework Ward and Peppard. Framework ini dipilih karena memiliki kelebihan yaitu mempunyai alat analisis yang lengkap, tidak hanya berfokus kepada kondisi SI namun juga memperhatikan aspek bisnis internal dan eksternal.

Qashlim, dkk (2019), hasil penelitiannya menyimpulkan bahwa integrasi sistem informasi dapat menghasilkan data yang lebih akurat bagi manajemen tingkat atas untuk mengambil keputusan pasar. Sistem yang terintegrasi ketika diimplementasikan akan memungkinkan kinerja terbaik di semua sektor, meningkatkan pengaruh kinerja pada pengurangan biaya keuangan dan operasional [2].

Penelitian oleh Solihin \& Wibisono (2017), dimana output yang dihasilkan berupa arsitektur data, arsitektur aplikasi dan arsitektur teknologi yang mendukung proses bisnis Perguruan Tinggi pada Universitas Pembangunan Nasional Veteran Jakarta yang berisi rancangan Arsitektur dan Tata Kelola TI yang dilengkapi dengan Roadmap Implementasi Program dan Proyek TI sebagai dokumen rencana TI untuk mendukung pencapaian sasaran strategik [3].

Penelitian berikutnya dilakukan oleh Nugraha, dkk (2020) bertujuan untuk menjawab permasalahan pemanfaatan SI di lingkungan Universitas xyz, adapun hasil identifikasi dari perencanaan strategis sistem informasi adalah terbentuknya portofolio aplikasi SI dan manajemen pengolahan SI sehingga tujuan untuk menyusun perencanaan strategis sistem informasi di Universitas xyz sudah terpenuhi dengan menggunakan metode value chain analysis [4].

Selain itu ada juga penelitian yang dilakukan oleh Alit \& Idhom (2017), dalam penelitiannya memberikan usulan rancangan sistem strategis dan teknologi informasi. Rekomendasi yang diberikan berupa nasehat atau sistem informasi teknologi informasi yang telah di selaraskan dengan visi, misi dan tujuan organisasi [5].

Syarendra and Kristanto (2020), dalam penelitian dengan metode ward and peppard menyimpulkan bahwa hasil analisa menunjukan efisiensi biaya dengan perencanaan bisnis yang matang [6].

Penelitian berikut oleh Febrianti, dkk (2020), menghasilkan portofolio strategi bisnis SI berupa

penambahan aplikasi baru seperti ERP, modul CRM, sistem keuangan, dan data pihak ketiga aplikasi koleksi untuk mendukung strategi bisnis SI [7].

Penelitian selanjutnya oleh Gaol, dkk (2020), merekomendasikan beberapa aplikasi yang dapat menyelesaikan permasalahan yang biasa dialami perusahaan seperti integrasi sistem dan otomasi proses bisnis untuk mencapai proses bisnis yang lebih efisien dan efektif [8].

Pada penelitian ini difokuskan pada perencanaan strategi SI mengacu pada model perencanan strategis Ward and Peppard, karena mencakup tentang informasi apa saja yang harus 
dihasilkan untuk organisasi, Metode perencanaan strategis SI dari Ward and Peppard berfungsi untuk menghasilkan portofolio rencana strategis SI yang menambah nilai bisnis dari organisasi, dengan kata lain terdapat keselarasan dengan strategi bisnis organisasi. Metode ini juga memastikan bahwa rencana strategis yang dihasilkan dapat dievaluasi.

\section{LANDASAN TEORI}

Strategi adalah prioritas atau arah keseluruan yang luas yang diambil oleh organisasi untuk mencapai tujuan organisasi (Basri, 2004) [9]. Strategi SI lebih menekankan pada penentuan aplikasi sistem informasi yang dibutuhkan oleh organisasi. Sedangkan strategi TI lebih menekankan pada pemilihan teknologi, infrastruktur dan keahlian khusus yang terkait (Ward \& Peppard, 2002) [10]. Hubungan antara strategi TI, strategi SI dan strategi bisnis dapat dilihat pada Gambar 1.

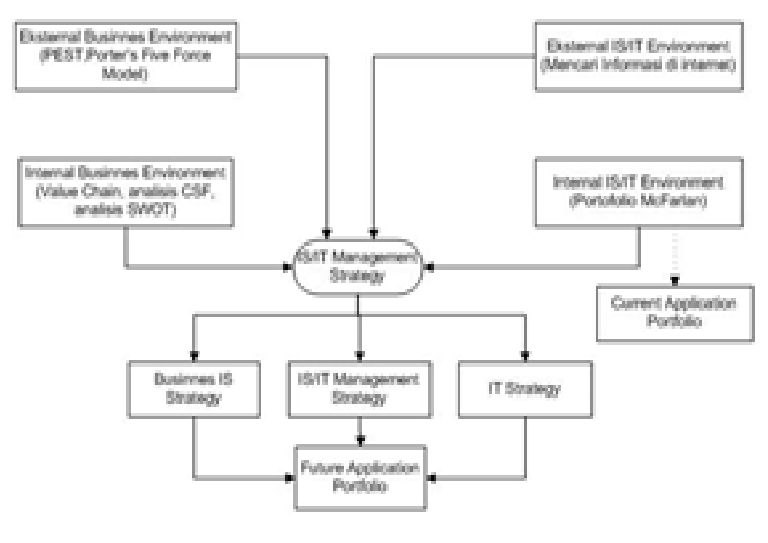

Gambar 1. Model Perencanaan Strategis SI/TI (Ward and Peppard, 2002)

Metode Analisis Perencanaan Strategis Sistem Informasi:

a. Analisis Value Chain

Analisa Value Chain dilakukan untuk memetakan seluruh proses kerja yang terjadi dalam organisasi menjadi dua kategori aktivitas, yaitu aktivitas utama dan aktivitas pendukung (Wedhasmara, 2009) [11]. Mengacu pada dokumen organisasi yang menyebutkan tugas dan fungsi setiap unit kerja berdasarkan pengamatan yang dilakukan terhadap proses kerja yang terjadi di masing-masing unit kerja, secara diagram Value Chain dapat terlihat seperti Gambar 2.

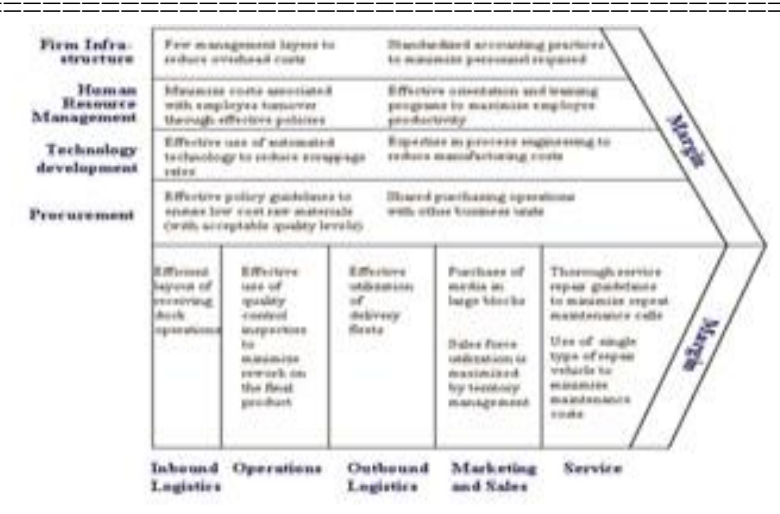

Gambar 2. Value Chain (Ward and Peppard, 2002)

\section{b. Analisis SWOT}

Analisis Strength, Weakness, Opportunity, Threat (SWOT) adalah identifikasi berbagai faktor strategi internal (kekuatan dan kelemahan) dan eksternal (peluang dan ancaman) perusahaan untuk merumuskan strategi perusahaan dengan memaksimalkan kekuatan (strength) dan peluang (opportunity), namun secara bersamaan dapat meminimalkan kelemahan (weakness) dan ancaman (threat) (Saragih \& Harisno, 2014) [12]. Analisis SWOT dilakukan dengan mengidentifikasi kekuatan dan faktor-faktor positif yang berasal dari internal organisasi, kelemahan dan faktor-faktor negatif dari internal, peluang dan keuntungan dari faktor eksternal dan ancaman yang dipengaruhi oleh faktor eksternal. Setelah mengidentifikasi analisis SWOT kemudian analisis tersebut dipetakan dalam empat kategori, seperti yang terlihat pada Tabel.1.

Tabel 1. SWOT (Ward and Peppard, 2002)

\begin{tabular}{|c|c|c|}
\hline PELUANG (O) & $\begin{array}{c}\text { KEKUATAN } \\
\text { (S) }\end{array}$ & $\begin{array}{c}\text { KELEMAHAN } \\
\text { (W) }\end{array}$ \\
\hline ANCtrategi untak \\
$\begin{array}{c}\text { Memantascian peluang } \\
\text { untuk mendayagunakan } \\
\text { kekuatan. } \\
\text { (Strategi S-O) }\end{array}$ & $\begin{array}{c}\text { Strategi untuk } \\
\text { Memantaatcan peluang } \\
\text { untuk mengatasi kelemahan } \\
\text { (Strategi W-O) }\end{array}$ \\
\hline ANCAMAN(T) & $\begin{array}{c}\text { Strategi untak } \\
\text { Mengatasi ancaman } \\
\text { dengan jalan } \\
\text { mendayagunakan } \\
\text { kekuatan. } \\
\text { (Strategi S-T) }\end{array}$ & $\begin{array}{c}\text { Menghindari ancaman } \\
\text { sekaligus melindungi } \\
\text { kelemahan } \\
\text { (Strategi W-T) }\end{array}$ \\
\hline \hline
\end{tabular}

\section{c. Analisa Critical Success Factor (CSF)}

Analisis Critical Successor Factor (CSF) merupakan suatu ketentuan dari organisasi dan lingkungannya yang berpengaruh pada keberhasilan atau kegagalan. CSF dapat 
ditentukan jika objektif organisasi telah diidentifikasi. Tujuan dari CSF adalah menginterpretasikan objektif secara lebih jelas untuk menentukan aktivitas yang harus dilakukan dan informasi apa yang dibutuhkan. Peranan Critical Successor Factor (CSF) dalam perencanaan strategis adalah sebagai penghubung antara strategi bisnis organisasi dengan strategi SI-nya, memfokuskan proses perencanaan strategis SI pada area yang strategis, memprioritaskan usulan aplikasi SI dan mengevaluasi strategi SI.

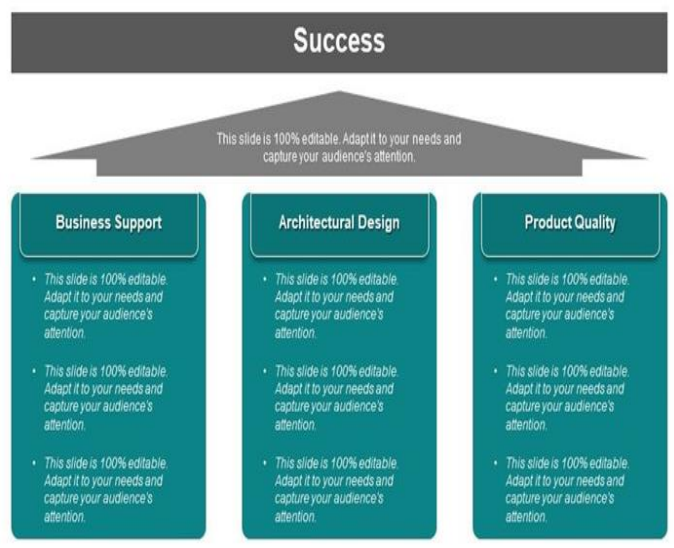

Gambar 3. Critical Successor Factor (Ward and Peppard, 2002)

\section{d. Analisis PEST}

Tabel 2. PEST (Ward and Peppard, 2002)



1. Faktor Politik Meliputi kebijakan pemerintahan, masalah-masalah hukum, serta mencakup aturan-aturan formal dan informal dari lingkungan dimana Universitas Kristen Indonesia Maluku melakukan kegiatannya.

2. Faktor Ekonomi Meliputi semua faktor yang mempengaruhi daya minat masyarakat dan mempengaruhi iklim berbinis Universitas
Kristen Indonesia Maluku

3. Faktor Sosial Meliputi semua faktor yang dapat mempengaruhi kebutuhan masyarakat dan mempengaruhi ukuran dari besarnya pangsa pasar yang ada.

4. Faktor Teknologi Meliputi semua hasil yang dapat membantu dalam menghadapi tantangan bisnis dan mendukung efisiensi proses bisnis dalam Universitas Kristen Indonesia Maluku

\section{e. Analisis Porter's Five Force}

Menurut Porter (1998), analisis ini digunakan untuk mengetahui keunggulan posisi kompetisi saat ini dan yang akan dihadapi di masa mendatang, sehingga perusahaan dapat meningkatkan kekuatan, mengantisipasi kelemahan dan akan menghindari perusahaan dalam pengambilan keputusan yang salah [13]. Gambar 4 menunjukkan model lima kekuatan kompetisi menurut Porter.

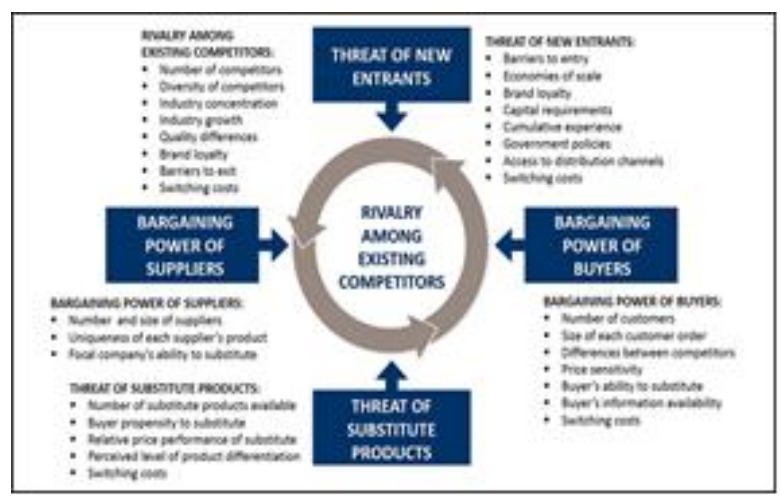

Gambar 4. Analisis Porter's Five Force (Porter, 1998)

\section{f. Mc Farlan's Strategic Grid}

Portofolio aplikasi McFarlan digunakan untuk menilai kontribusi SI/TI Universitas Kristen Indonesia Maluku secara keseluruhan dan efeknya terhadap kesuksesan bisnis. Hasil dari pemetaan tersebut dapat digambarkan seperti yang terlihat pada Tabel 3 . 
Tabel 3. Mc Farlan's Strategic Grid (Ward \& Peppard, 2002)

\begin{tabular}{|l|l|}
\hline \multicolumn{1}{|c|}{ STRATEGIC } & HIGH POTENTIAL \\
\hline $\begin{array}{l}\text { - Applications that } \\
\text { are critical to } \\
\text { sustaining future } \\
\text { business strategy }\end{array}$ & $\begin{array}{l}\text { - Applications that } \\
\text { may be important } \\
\text { in achieving future } \\
\text { success }\end{array}$ \\
\hline $\begin{array}{l}\text { Applications on which } \\
\text { the organization } \\
\text { currently depends } \\
\text { for success }\end{array}$ & $\begin{array}{l}\text { - Applications that } \\
\text { are valuable but } \\
\text { not critical to } \\
\text { success }\end{array}$ \\
\hline KEY OPERATIONAL & \multicolumn{1}{c|}{ SUPPORT } \\
\hline
\end{tabular}

III. METODE

Cara-cara yang akan diambil antara lain dengan wawancara, observasi langsung dan studi atas dokumen-dokumen terkait dan studi literatur.

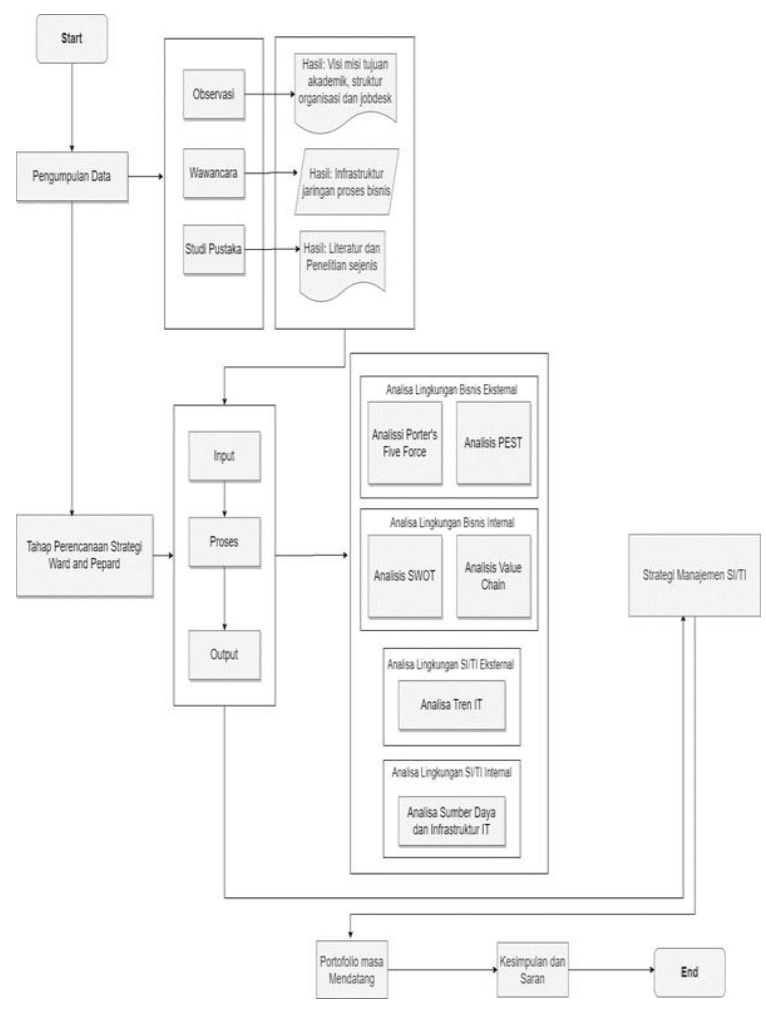

Gambar 5. Alur Penelitian

Wawancara mengenai kondisi SI dengan kepala-kepala seksi atau sub bagian lainnya juga yang diwawancarai mengenai rencana strategi dan sasaran kinerja Universitas Kristen Indonesia Maluku. Informasi juga akan diperoleh dengan observasi langsung. Dalam konteks penelitian ini observasi langsung adalah pengamatan langsung dari kondisi di Universitas Kristen Indonesia Maluku yang dilakukan tanpa alat khusus. Selain wawancara dan observasi, sumber informasi lainnya mengenai Universitas Kristen Indonesia Maluku adalah dari dokumen-dokumen. Studi dokumen akan dilaksanakan dengan mengumpulkan dan mempelajari berbagai dokumen yang terkait Universitas Kristen Indonesia Maluku antara lain rencana strategis, rencana kinerja, peraturan-peraturan, inventaris, dan dokumen-dokumen lainnya yang mungkin diperlukan. Studi literatur juga akan dilaksanakan pada tahap ini. Literatur-literatur yang akan digunakan antara lain karya tulis, makalah, buku referensi, artikel dan sumber-sumber lainnya.

\section{HASIL DAN PEMBAHASAN}

A. Analisa Lingkungan Bisnis Internal

Tools yang digunakan dalam menganalisis strategi bisnis organisasi adalah Critical Success Factor (CSF). Untuk menganalisis proses bisnis organisasi digunakan value chain. Sedangkan untuk mengidentifikasikan kekuatan, kelemahan, peluang, dan ancaman perusahaan digunakan analisis SWOT. Hasil pengumpulan data kemudian diterjemahkan didalam bentuk analisa sebagai berikut:

a) Analisa Critical Success Factor (CSF)

Berdasarkan tujuan Institusi yang di dapat dari rencana strategis (Renstra) Universitas Kristen Indonesia Maluku sebagai input untuk penggunaan teknik analisis Critical Success Factor (CSF) dapat dilihat seperti pada tabel 4 dibawah ini:

Tabel 4. Analisis Critical Success Factor (CSF) Universitas Kristen Indonesia Maluku

\begin{tabular}{|c|c|c|}
\hline Tujuan & $\begin{array}{c}\text { Critical } \\
\text { Success } \\
\text { Factor }\end{array}$ & Unit \\
\hline $\begin{array}{l}\text { - Menyelenggara } \\
\text { kan pendidikan } \\
\text { tinggi untuk } \\
\text { menghasilkan } \\
\text { lulusan yang } \\
\text { unggul dan } \\
\text { berdaya saing } \\
\text { tinggi dalam } \\
\text { bidang } \\
\text { pendidikan, } \\
\text { sains, } \\
\text { teknologi. }\end{array}$ & $\begin{array}{l}\text { - } \text { Ketersediaa } \\
\text { n media } \\
\text { sarana } \\
\text { pendidikan. } \\
\text { - Adanya } \\
\text { metode } \\
\text { yang tepat } \\
\text { dalam } \\
\text { penyelengg } \\
\text { araan } \\
\text { pendidikan. } \\
\text { - Ketersediaa }\end{array}$ & $\begin{array}{l}\text { - Seluruh } \\
\text { fakultas } \\
\text { - Biro } \\
\text { Administra } \\
\text { si } \\
\text { Akademik } \\
\text { dan } \\
\text { Kemahasis } \\
\text { waan } \\
\text { - UPT } \\
\text { Perpustaka } \\
\text { an }\end{array}$ \\
\hline
\end{tabular}




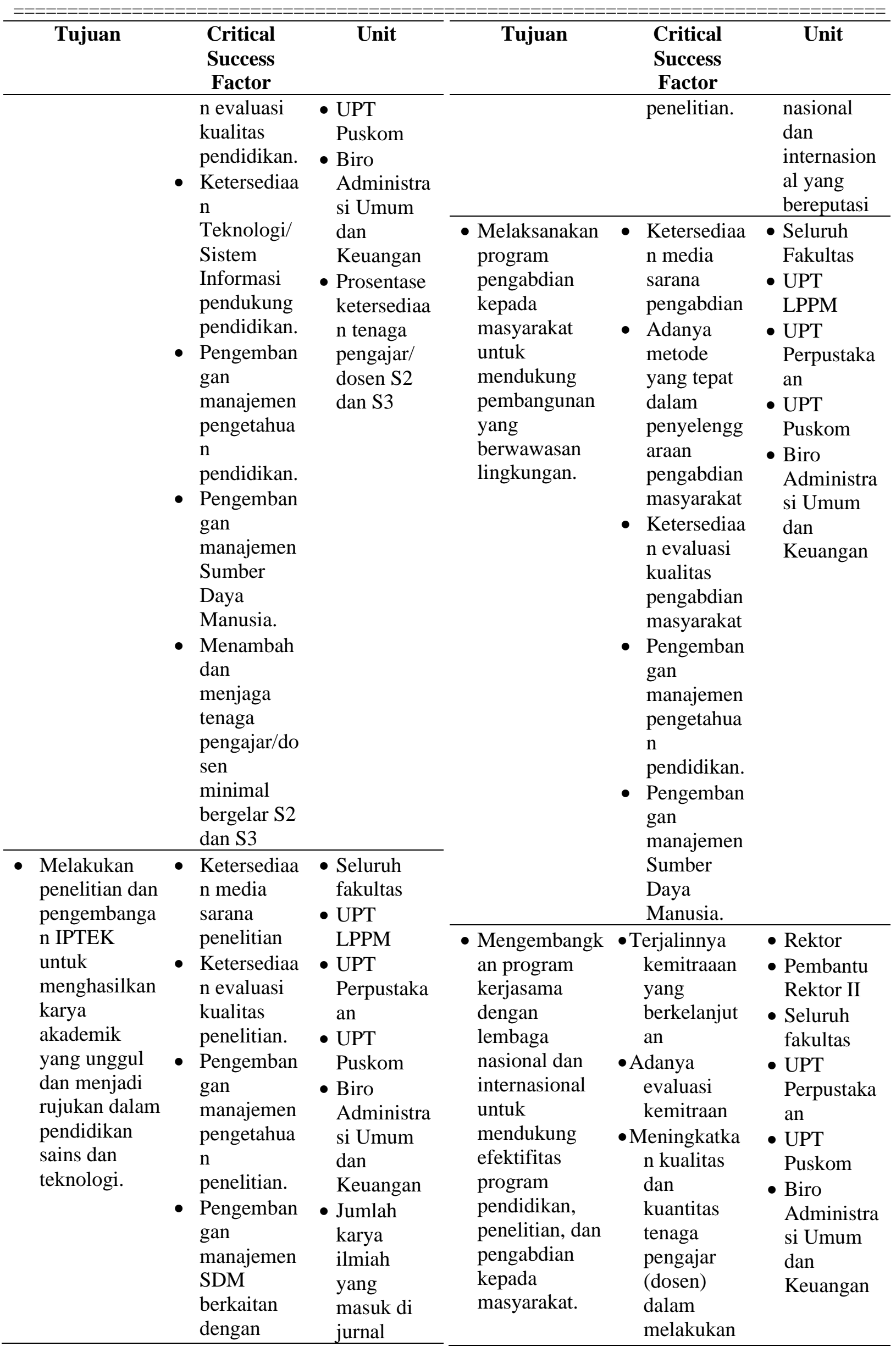




\begin{tabular}{|c|c|c|}
\hline Tujuan & $\begin{array}{c}\text { Critical } \\
\text { Success } \\
\text { Factor }\end{array}$ & Unit \\
\hline & $\begin{array}{l}\text { penulisan } \\
\text { karya } \\
\text { ilmiah } \\
\text { khususnya } \\
\text { bidang } \\
\text { penelitian } \\
\text { dan } \\
\text { keikutsertaa } \\
\text { n dalam } \\
\text { forum- } \\
\text { forum } \\
\text { ilmiah }\end{array}$ & \\
\hline $\begin{array}{l}\text { - Menjadi } \\
\text { Universitas di } \\
\text { Ambon, } \\
\text { Maluku yang } \\
\text { menghasilkan } \\
\text { SDM } \\
\text { memiliki } \\
\text { kemampuan } \\
\text { entrepreneurs } \\
\text { hip yang } \\
\text { handal, } \\
\text { menyiapkan } \\
\text { sumber daya } \\
\text { manusia yang } \\
\text { memiliki } \\
\text { keahlian dan } \\
\text { keterampilan } \\
\text { profesional } \\
\text { yang siap } \\
\text { mengisi } \\
\text { kebutuhan } \\
\text { lapangan } \\
\text { kerja }\end{array}$ & $\begin{array}{l}\text { - Mengadaka } \\
\text { n training } \\
\text { dan Seminar } \\
\text { pengemban } \\
\text { gan } \\
\text { kepribadian } \\
\text { pada } \\
\text { mahasiswa }\end{array}$ & $\begin{array}{l}\text { - Prosentase } \\
\text { lulusan } \\
\text { Universitas } \\
\text { Kristen } \\
\text { Indonesia } \\
\text { Maluku } \\
\text { yang sudah } \\
\text { bekerja di } \\
\text { perusahaan } \\
\text { swasta dan } \\
\text { pemerintah } \\
\text { an } \\
\text { - Prosentase } \\
\text { jumlah } \\
\text { mahasiswa } \\
\text { yang } \\
\text { berwirasw } \\
\text { asta }\end{array}$ \\
\hline
\end{tabular}

b) Analisa SWOT

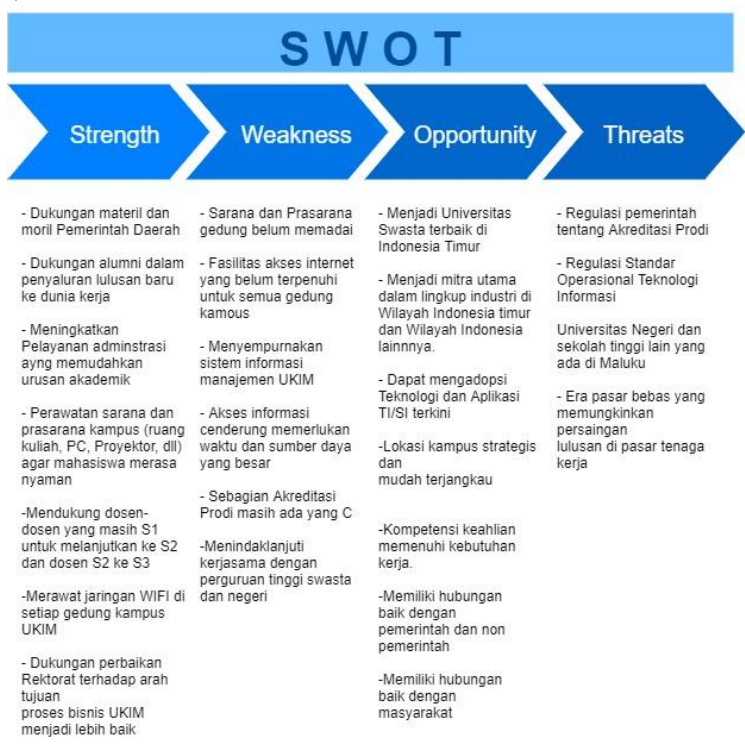

Gambar 6. Analisa SWOT Universitas Kristen Indonesia Maluku

Tabel 5. Matrix SWOT

$\begin{array}{cc}\text { Strength } & \text { Weakness } \\ \text { (Kekuatan) } & \text { (Kelemahan) }\end{array}$

\begin{tabular}{|c|c|c|}
\hline & $\begin{array}{l}\text { Strategi SO } \\
\text { 1.Pertahankan } \\
\text { dan } \\
\text { tingkatkan } \\
\text { fasilitas- } \\
\text { fasilitas } \\
\text { unggulan } \\
\text { yang dimiliki } \\
\text { Universitas } \\
\text { Kristen } \\
\text { Indonesai } \\
\text { Maluku. } \\
\text { 2.Cepat } \\
\text { berdaptasi } \\
\text { dengan setiap } \\
\text { perubahan } \\
\text { regulasi } \\
\text { pemerintah } \\
\text { dalam bidang } \\
\text { pendidikan } \\
\text { 3. Merawat atau } \\
\text { menambah } \\
\text { fasilitas agar } \\
\text { proses } \\
\text { kegiatan } \\
\text { pendidikan } \\
\text { meningkat }\end{array}$ & $\begin{array}{l}\text { Strategi WO } \\
\text { 1.Memaksimalkan } \\
\text { promosi } \\
\text { Universitas } \\
\text { Kristen } \\
\text { Indonesai } \\
\text { Maluku lebih } \\
\text { baik lagi agar } \\
\text { menjaring } \\
\text { mahasiswa baru } \\
\text { lebih banyak lagi } \\
\text { 2.Meningkatkan } \\
\text { sarana dan } \\
\text { prasarana } \\
\text { 3. Mempercepat } \\
\text { proses akreditasi } \\
\text { bagi fakultas } \\
\text { yang masih } \\
\text { berakreditasi C. } \\
\text { 4.Memberikan } \\
\text { pelatihan kepada } \\
\text { SDM, baik staff } \\
\text { maupun dosen } \\
\text { yang sesuai } \\
\text { dengan } \\
\text { kebutuhan. } \\
\text { 5.Perbaikan dan } \\
\text { peningkatan }\end{array}$ \\
\hline
\end{tabular}




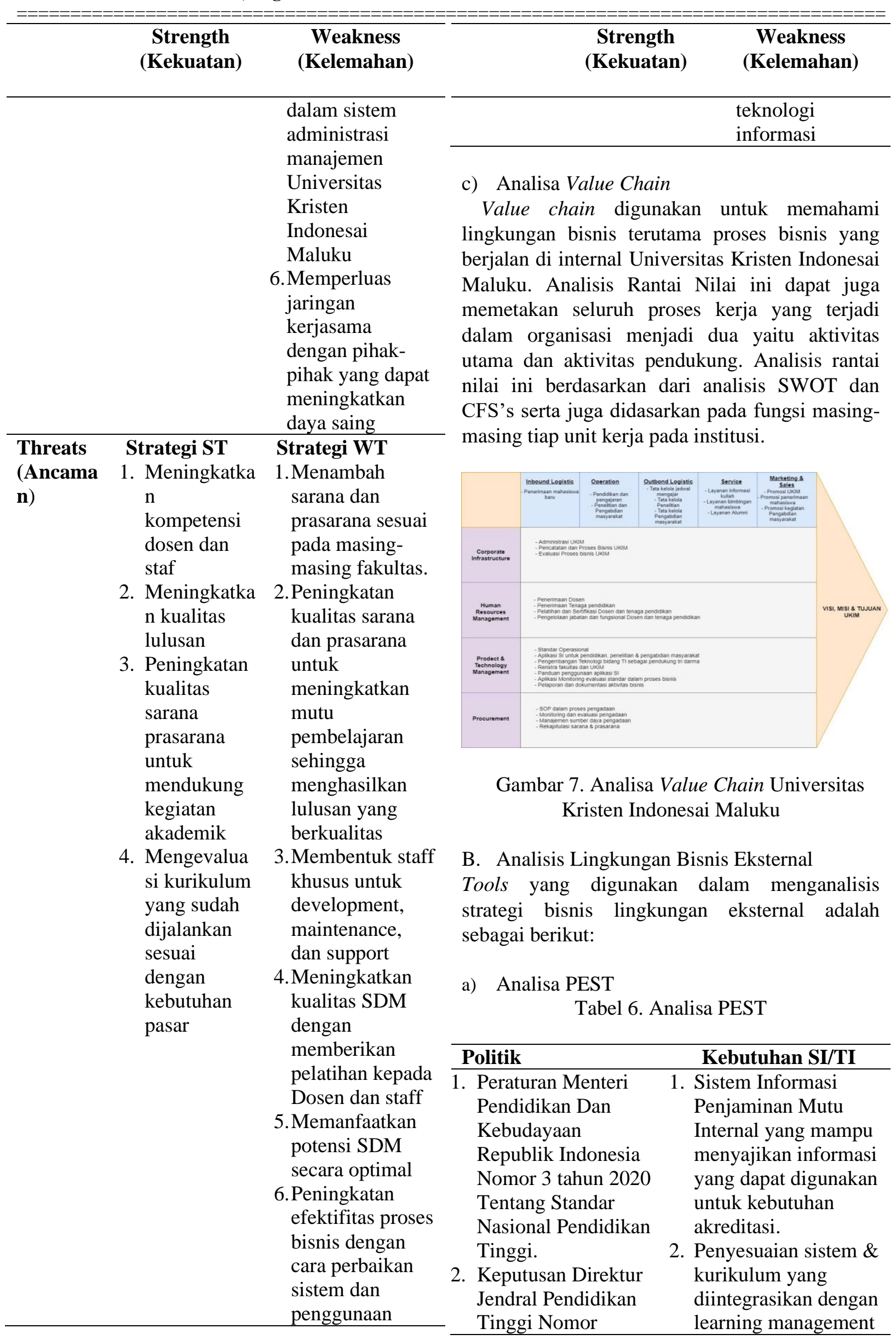




$=================$
116/UKIM.H/SK/20
18 Rencana Strategis
UKIM, 2018 - 2027
3. Permenristekdikti RI
No.44 Tahun 2015
tentang Standar
Nasional Pendidikan
Tinggi.
4. Undang Undang Ri
No. 12 Tahun 2012
Tentang Pendidikan
Tinggi.

5. Peraturan

Pemerintah No. 4

Tahun 2014 Tentang

Penyelenggaraan

Pendidikan Tinggi

Dan Pengelolaan

Perguruan Tinggi.

6. Permendikbud No.

109 Tahun 2013

Tentang

Penyelenggaraan

Pendidikan Jarak

Jauh Di Pendidikan

Tinggi.

7. Permendikbud No.

50 Tahun 2014

Tentang Satuan

Penjaminan Mutu

Internal (Spmi).

\begin{tabular}{l}
\hline \multicolumn{1}{c}{ Ekonomi } \\
\hline 1. Dalam sektor \\
perikanan, maluku \\
termasuk \\
penyumbang besar \\
produksi ikan segar \\
nasional \\
2. Hasil rempah \\
cengkeh dan pala \\
jadi komoditi utama \\
hasil bumi di wilayah \\
Maluku \\
3. Potensi Maluku \\
sebagai daerah \\
tujuan wisata
\end{tabular}

sistem pendidikan

jarak jauh ataupun

blended learning

tanpa menambah

SKS. Penyesuaian ini termasuk fleksibilitas

dalam penerapan

model semester atau

triwulan.

3. Perguruan tinggi

harus mempersiapkan

SDM yang

memahami 4

komponen keilmuan:

1) mengubah mindset

dan talent; 2)

memiliki pemahaman

humanity; 3)

memiliki kompetensi

minimal $4 \mathrm{C}$ yang

terampil dalam

pemanfaatan sarana

dan prasarana di era

revolusi industri 4.0,

dan; 4) memiliki

kompetensi teknis

praktis yang

difasilitasi melalui

berbagai program

peningkatan

kompetensi.

\section{Kebutuhan SI/TI}

1. Sistem informasi

yang dapat

menampilkan

informasi profil

Universitas Kristen

Indonesia Maluku

sebagai pencetak

tenaga kerja terampil.

2. Kemitraan dengan

industri dalam

perumusan

kurikulum,

pelaksanaan teaching

industry, program

multi entry multi exit

system dan magang

industri, dan

penjaminan mutu

untuk

penyelenggaraan

pendidikan vokasi

yang bermutu
3. Perguruan tinggi

perlu

mengembangkan

resource sharing khas

era revolusi Industri

4.0 dan revolusi

industri yang lebih

tinggi, yang

mendukung proses

pembelajaran dan

penelitian yang dapat

mendongkrak potensi

ilmu pengetahuan

Indonesia.

\begin{tabular}{ll}
\hline \multicolumn{1}{c}{ Sosial } & \multicolumn{1}{c}{ Kebutuhan SI/TI } \\
\hline 1.Perusahaan di bidang & 1.Sistem informasi \\
perikanan besar di & yang menghubungkan \\
Maluku & tiga pihak yaitu \\
berkontribusi bagi & kampus, masyarakat \\
pengembangan & dan pemerintah dalam \\
masyarakat di sekitar & pemanfaatan dana \\
lokasi usaha & bantuan untuk \\
perusahaan. & beasiswa calon \\
& mahasiswa.
\end{tabular}

Kebutuhan SI/TI

1.Perkembangan
teknologi informasi
dan komunikasi
seperti aplikasi web,
aplikasi mobile dan
cloud computing.

1. Sistem informasi yang dikembangkan harus mendukung berbagai platform.

2. Perguruan tinggi segera menyiapkan sarana prasarana pembelajaran model daring dengan memanfaatkan sarana dan prasarana khas era revolusi industri 4.0 (smart class room, augmented reality, artificial intelligence, virtual reality, data analytic, dan big data) yang sifatnya tidak hanya berfokus pada peningkatan akses dan mutu, tetapi juga efisiensi prosesnya. 
b) Analisa Five Force Model

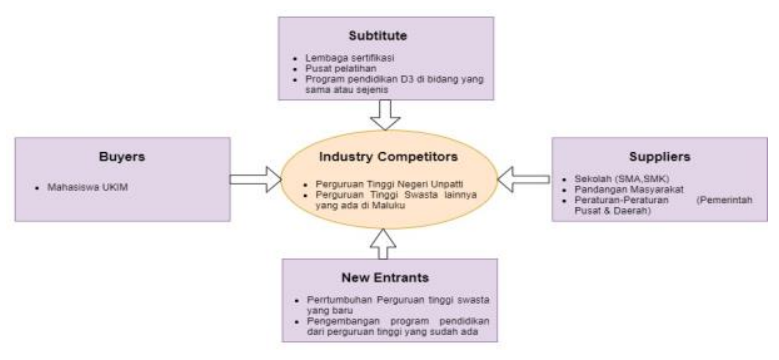

Gambar 8. Analisa Five Force Model

Universitas Kristen Indonesia Maluku

Tabel 6. Analisa Analisis Lingkungan Bisnis Eksternal menggunakan Five Force Universitas Kristen Indonesai Maluku

\begin{tabular}{|c|c|c|}
\hline Forces & Peluang & Ancaman \\
\hline $\begin{array}{l}\text { Pen } \\
\text { dat } \\
\text { ang } \\
\text { Bar } \\
\mathrm{u}\end{array}$ & $\begin{array}{l}\text { 1. Masih sedikit } \\
\text { sekolah tinggi } \\
\text { dan } 1 \\
\text { universitas } \\
\text { negeri dengan } \\
\text { program } \\
\text { sejenis di } \\
\text { Maluku } \\
\text { 2. Universitas } \\
\text { Kristen } \\
\text { Indonesai } \\
\text { Maluku } \\
\text { memiliki } \\
\text { hubungan } \\
\text { masyarakat } \\
\text { sekitar dan } \\
\text { lembaga- } \\
\text { lembaga } \\
\text { pemerintah } \\
\text { maupun non- } \\
\text { pemerintah }\end{array}$ & $\begin{array}{l}\text { 1. Peraturan } \\
\text { pemerintah } \\
\text { daerah } \\
\text { tentang } \\
\text { pendirian } \\
\text { sekolah } \\
\text { tinggi/perg } \\
\text { uruan } \\
\text { tinggi } \\
\text { untuk } \\
\text { kemajuan } \\
\text { pendidikan } \\
\text { di Maluku } \\
\text { sehingga } \\
\text { memudahk } \\
\text { an } \\
\text { seseorang } \\
\text { atau } \\
\text { kelompok } \\
\text { untuk } \\
\text { membentuk } \\
\text { lembaga } \\
\text { pendidikan } \\
\text { 2. Penyesuaia } \\
\text { n Prodi dan } \\
\text { Kurikulum } \\
\text { dengan } \\
\text { mengintegr } \\
\text { asikan } \\
\text { literasi } \\
\text { baru untuk } \\
\text { merespon } \\
\text { Revolusi } \\
\text { Industri } 4.0\end{array}$ \\
\hline
\end{tabular}

\begin{tabular}{|c|c|c|}
\hline Forces & Peluang & Ancaman \\
\hline $\begin{array}{l}\text { Pel } \\
\text { ang } \\
\text { gan } \\
\text { (lul } \\
\text { usa } \\
\mathrm{n} \\
\mathrm{SM} \\
\mathrm{A} / \mathrm{S} \\
\mathrm{MK} \\
\text { sed } \\
\text { eraj } \\
\text { at) }\end{array}$ & $\begin{array}{ll}\text { 1. } & \text { Biaya } \\
\text { pendidikan di } \\
\text { Universitas } \\
\text { Kristen } \\
\text { Indonesai } \\
\text { Maluku } \\
\text { terjangkau }\end{array}$ & $\begin{array}{l}\text { 1. Keinginan } \\
\text { pelanggan } \\
\text { (lulusan } \\
\text { SMA/SMK } \\
\text { sederajat) } \\
\text { dengan } \\
\text { kualitas } \\
\text { pendidikan } \\
\text { yang tinggi }\end{array}$ \\
\hline $\begin{array}{l}\text { Pes } \\
\text { ain } \\
\text { g }\end{array}$ & $\begin{array}{l}\text { 1. Universitas } \\
\text { Kristen } \\
\text { Indonesia } \\
\text { Maluku memiliki } \\
\text { beberapa mitra } \\
\text { proses bisnis }\end{array}$ & $\begin{array}{l}\text { 1. Pesaing } \\
\text { yang sudah } \\
\text { lebih dahulu } \\
\text { berdri dan } \\
\text { memiliki } \\
\text { jaringan } \\
\text { yang luas } \\
\text { sehingga } \\
\text { proses bisnis } \\
\text { pesaing } \\
\text { lebih kuat }\end{array}$ \\
\hline $\begin{array}{l}\text { Pro } \\
\text { duk } \\
\text { Sub } \\
\text { titu } \\
\text { si }\end{array}$ & $\begin{array}{l}\text { 1. Lebih banyak } \\
\text { memiliki } \\
\text { instrument- } \\
\text { instrumen yang } \\
\text { menunjang } \\
\text { pendidikan } \\
\text { seperti } \\
\text { infrastruktur. }\end{array}$ & $\begin{array}{l}\text { 1. Tumbuh } \\
\text { pesatnya } \\
\text { jenjang } \\
\text { pendidikan } 3 \\
\text { tahun dan } \\
\text { sekolah } \\
\text { tinggi. }\end{array}$ \\
\hline $\begin{array}{l}\text { Pe } \\
\text { mas } \\
\text { ok }\end{array}$ & $\begin{array}{l}\text { 1. Memiliki } \\
\text { hubungan baik } \\
\text { dan kerja sama } \\
\text { dengan beberapa } \\
\text { SMA/SMK di } \\
\text { Maluku }\end{array}$ & $\begin{array}{l}\text { 1. Pentingnya } \\
\text { Akreditasi } \\
\text { "A" sebagai } \\
\text { jaminan } \\
\text { mutu } \\
\text { pendidikan } \\
\text { di semua } \\
\text { fakultas } \\
\text { Universitas } \\
\text { Kristen } \\
\text { Indonesai } \\
\text { Maluku }\end{array}$ \\
\hline
\end{tabular}

c) Portofolio Rencana Strategis $S$

Ditinjau dari hasil analisis kebutuhan bisnis dan infromasi, maka dapat ditentukan Portofolio Strategi Sistem Informasi untuk menentukan portofolio aplikasi Sistem Informasi Universitas Kristen Indonesia Maluku yang harus dibangun. Sedangkan strategi TI menentukan infrastruktur 
TI yang diperlukan untuk mendukung strategi SI.

1. Strategi Manajemen SI

- Melakukan evaluasi strategi manajemen SI yang sudah berjalan menurut gambaran arsitektur informasi

- Pemetaan portofolio aplikasi SI yang baru maupun yang akan di update.

2. Strategi Implementasi Sistem Informasi

- Penambahan SDM di bidang IT yang kompeten

- Melakukan pengembangan sistem basis data dan jaringan (Oracle, CISA, Cisco dan Mikrotik)

- Migrasi ke server berbasis cloud

- Melakukan pendataan terhadap penggunaan berbagai jenis software yang digunakan pada setiap divisi dan perangkat keras yang digunakan pada infrastruktur jaringan yang berjalan saat ini.

- Mengoptimalkan penggunaa SI untuk meningkatkan kualitas proses belajar mengajar

- Menjaga ketersediaan dan kemudahan akses internet di lingkungan Universitas Kristen Indonesia Maluku dengan mengalokasikan bandwith sesuai dengan kebutuhan.

- Menambah aplikasi SI untuk menunjang kelangsungan bisnis Universitas Kristen Indonesia Maluku dan terintegrasi dalam suaru website institusi (SIPMB, Sistem Informasi Alumni, dll)

- Mengevaluasi strategi SI/TI yang sudah di terapkan pada periode yang sebelumnya.

d) Mc Farlan Strategic Grid

Berikut adalah portofolio perubahan analisa kondisi SI yang diususlkan ada di Universitas Kristen Indonesia Maluku yang ditunjukkan pada tabel 7 dibawah ini.

Tabel 7. Future Application Portofolio Mc Farlan Strategic Grid

\begin{tabular}{ll}
\hline \multicolumn{1}{c}{ Strategic } & \multicolumn{1}{c}{ High Potential } \\
\hline Website Universitas & SI Pendaftaran \\
Kristen Indonesia & Mahasiswa Baru \\
Maluku(Update) & (Update) \\
SI Penjamin Mutu & SI Manajemen \\
(Update) & Kemahasiswaan \\
SI Akademik (Update) & (Update) \\
SI Alumni dan Tracer & SI Manajemen Data \\
(Update) & Dosen dan Pegawai \\
\hline
\end{tabular}

\begin{tabular}{ll}
\hline SI Kerjasama (Baru) & (Baru) \\
E-Learning (Baru) & SI Keuangan (Update) \\
E-Library (Baru) & SI Loker (Baru) \\
SI Beasiswa (Baru) & E-Repositoy (Baru) \\
E-Research (Update) & \\
E-Procurement (Baru) & \\
\hline SI Jadwal Kuliah & Migration to Cloud \\
(Update) & System (Server) (Baru) \\
SI PKL dan Tugas & Internet (Update) \\
Akhir (Skripsi/Thesis) & IDS (Update) \\
(Update) & Mail System (Update) \\
SIM Pengabdian & PJJ (Baru) \\
masyarakat dan & SDM \\
Penelitian (Update) & \\
SI Presensi & \\
Pegawai/Dosen & \\
(Update) & \\
SI Inventaris (Baru) & \\
SI LPPM (Update) & \\
\hline \multicolumn{1}{c}{ Key Operational } & \multicolumn{1}{c}{ Support } \\
\hline
\end{tabular}

Prinsip teknologi terangkum dalam perancangan arsitektur teknologi enterprise sehingga dalam perancangan arsitektur teknologi akan lebih efisien. Penggunaan layanan cloud dapat mengurangi biaya, mampu menampung lalu lintas data yang banyak, dan efisien. Infrastruktur jaringan yang diusulkan dapat terlihat pada gambar 9 .

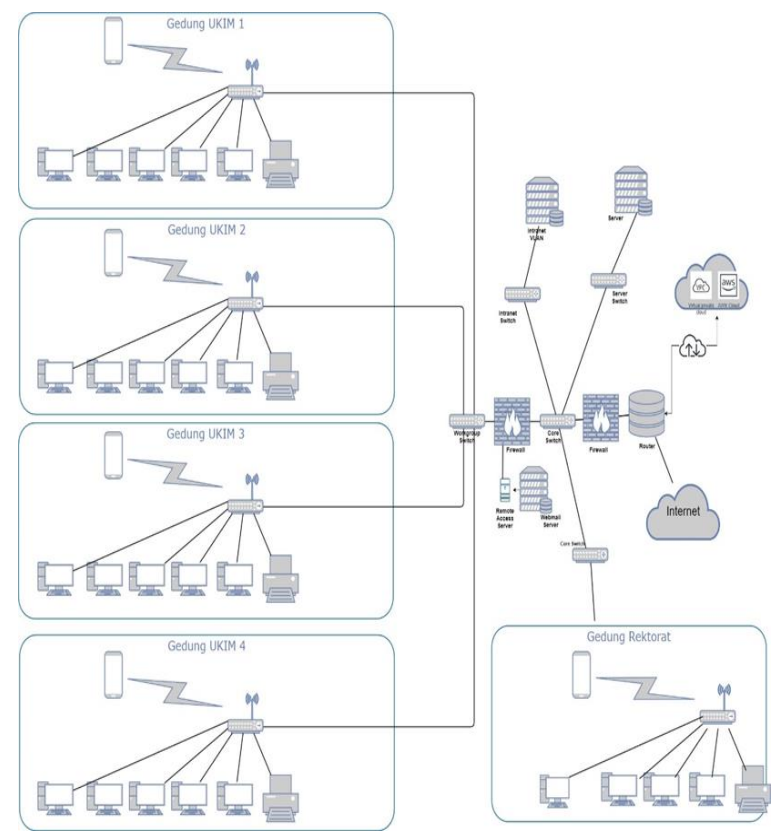

Gambar 9. Usulan Rancangan Struktur Jaringan 


\section{KESIMPULAN}

1. Beberapa faktor hambatan dalam mengimplementasi pelayanan berbasis teknologi digital adalah: koneksi internet yang tidak stabil, perpustakaan berbasis digital dan online belum terimplementasi, sistem informasi belum sepenuhnya terintegrasi, infrastruktur teknologi kurang andal (kekinian), keterbatasan anggaran dalam pengembangan teknologi, dan kekurangan SDM teknologi informasi.

Hasil perencanaan SI masa mendatang dengan menggunakan tools portofolio McFarlan dihasilkan sepuluh jenis aplikasi sistem informasi baru yang direncanakan akan dibuat dan enam belas jenis aplikasi yang dipertimbangkan untuk diperbaharui (update) dan usulan rancangan arsitektur jaringan berbasis cloud.

\section{DAFTAR PUSTAKA}

[1] J. C. Henderson and J. G. Sifonis, "The value of strategic IS planning: Understanding consistency, validity, and IS markets," $M I S Q$. Manag. Inf. Syst., 1988, doi: 10.2307/248843.

[2] A. Qashlim, Syarli, and Basri, "Industry System Integration of Drug Distribution on Pharmaceutical Installation Based on Supply Chain Management," 2019, doi: 10.1088/1742-6596/1244/1/012009.

[3] M. B. Solihin, Indra Permana; Wibisosno, "Perencanaan Strategik Sistem Informasi Dan Teknologi Informasi ( SI / TI ) Dengan Framework Zachman Di Universitas," Pros. SINTAK 2017, pp. 259-269, 2017, [Online]. Available:

https://www.unisbank.ac.id/ojs/index.php/sint ak/article/view/5531/1657.

[4] M. B. Nugraha, G. Pralebda, and R. S. Dewi, "Perencanaan Strategis Sistem Informasi Pada Universitas XYZ Menggunakan Metode Ward and Peppard," JURIKOM (Jurnal Ris. Komputer), vol. 7, no. 1, p. 34, 2020, doi: 10.30865/jurikom.v7i1.1788.

[5] R. I. Alit Mohammad, "Strategic Planning Of Sytem And Information Technology Based On Ward And Peppard(Case Study: State Junior High School 1 Waru Sidoarjo)," Pros. Int. Conf. Inf. Technol. Bus., no. 2017: INTERNATIONAL CONFERENCE ON INFORMATION TECHNOLOGY AND BUSINESS (ICITB) 3, pp. 50-54, 2017.

[6] J. D. Syarendra and A. B. Kristanto, "JURNAL AKSI Akuntansi dan Sistem Informasi Income in Ex-Karesidenan Madiun," J. Akutnansi dan Sist. Inf., vol. 5, no. 1 , pp. 37-40, 2020.

[7] K. D. Febriyanti, F. Samopa, and R. Ambarwati, "Strategic Planning for IS/IT of XYZ Internet Service Provider Using Ward and Peppard Method," IPTEK J. Proc. Ser., vol. 0, no. 5, p. 473, 2019, doi: 10.12962/j23546026.y2019i5.6407.

[8] F. L. Gaol, S. Rahayu, and T. Matsuo, "The development of information system with strategic planning for integrated system in the indonesian pharmaceutical company," Open Eng., vol. 10, no. 1, pp. 721-732, 2020, doi: 10.1515/eng-2020-0081.

[9] J. Allison, Michael; Kaye, Perencanaan Strategis Bagi Organisasi Nirlaba. 2005.

[10] J. Ward and J. Peppard, Success Factors in Strategic Information Systems. 2002.

[11] Ari Wedhasmara, "LANGKAH-LANGKAH PERENCANAAN STRATEGIS SISTEM INFORMASI DENGAN MENGGUNAKAN METODE WARD AND PEPPARD | Wedhasmara | Jurnal Sistem Informasi," Jsi, 2017.

[12] Saragih and Harisno, Rencana Strategis Teknologi Informasi (IT) dan Sistem Informasi (IS) pada proses Bisnis Perusahaan. 2014.

[13] M. E. Porter, "Competitive StrategyThe Free Press," New York, 1980. 